\title{
P Values and Confidence Intervals
}

The Canadian Journal of Psychiatry / La Revue Canadienne de Psychiatrie 202I, Vol. 66(4) 42I-422 (C) The Author(s) 2020 Article reuse guidelines: sagepub.com/journals-permissions DOI: $10.1177 / 0706743720962277$ TheCJP.ca | LaRCP.ca (S)AGE

\section{Scott B. Patten, MD, PhD' $\odot$ and David L. Streiner, PhD $^{2}$}

provides an estimate of effect and also a range of values that are consistent with the observed data at the specified level of confidence (usually $95 \%$ confidence intervals are reported). A confidence interval for a measure of effect, such as an odds ratio, provides all of the information provided by a statistical test and more. When a confidence interval does not include the null value (e.g., 1.0 in the case of an odds ratio; 0.0 for a standardized mean difference), the null hypothesis would have been rejected had a statistical test been used. However, if the interpretation of a confidence interval leads to a statement of significance, the same issues of multiple "testing" arise. Therefore, carefully planned and thoughtful data analysis is required in addition to the selection of the best statistical tools. The CJP endorses the ICMJE recommendations, and we encourage authors to avoid excessive reliance on $P$ values in reporting their analyses.

\section{Authors' Note}

Dr. Patten is supported by the Cuthbertson \& Fischer Chair in Pediatric Mental Health at the University of Calgary.

with random variation (at the 5\% level of confidence) even when the null hypothesis is not true, a type II error. Type II error can be understood as a "false negative" because it suggests a lack of difference between groups in the population when a difference does exist. By the same token, when the sample size is small, any chance effect that is significant will likely be large. ${ }^{3}$ For these reasons, the International Committee of Medical Journal Editors (ICMJE) recommends that authors should: "When possible, quantify findings and present them with appropriate indicators of measurement error or uncertainty (such as confidence intervals). Avoid relying solely on statistical hypothesis testing, such as $P$ values, which fail to convey important information about effect size and precision of estimates." This echoes a recommendation from the Task Force on Statistical Inference of the American Psychological Association, which states "It is hard to imagine a situation in which a dichotomous accept-reject decision is better than reporting an actual $P$ value or, better still, a confidence interval. ${ }^{4} \mathrm{~A}$ confidence interval

\section{Declaration of Conflicting Interests}

The author(s) declared no potential conflicts of interest with respect to the research, authorship, and/or publication of this article.

\section{Funding}

The author(s) received no financial support for the research, authorship, and/or publication of this article.

\footnotetext{
' Departments of Community Health Sciences and Psychiatry, University of Calgary, Alberta, Canada

2 Department of Psychiatry and Behavioural Neurosciences, McMaster University, Hamilton, Ontario, Canada
}

Corresponding Author:

Scott B. Patten, Mathison Centre for Mental Health Research \& Education, 4D66 TRW Building, 3280 Hospital Drive N. W., Calgary, Alberta, Canada T2N $4 Z 6$.

Email: patten@ucalgary.ca 


\section{ORCID iD}

Scott B. Patten (D) https://orcid.org/0000-0001-9871-4041

\section{References}

1. Hwang P, Hechtman L, Jimenez AC, et al. In response to "clinical characteristics associated with early phase psychosis and comorbid substance use": methodological concerns. Can J Psychiatry. 2021;66(2):183-184. doi: 10.1177/070674372 0947636.
2. Cookey J, McGavin J, Crocker CE, Matheson K, Stewart SH, Tibbo PG. A retrospective study of the clinical characteristics associated with alcohol and cannabis use in early phase psychosis. Can J Psychiatry. 2020;65(6):426-435.

3. Streiner DL.Sample size in clinical research: when is enough enough? J Pers Assess. 2006:87(3);259-260.

4. APA Task Force. Wilkinson, L, and Task Force on Statistical Inference APA Board of Scientific Affairs. Statistical methods in psychology journals: guidelines and explanations. Am Psychol. 1999:54(8);594-604. 